ARTICLE

\title{
Investigating the potential effectiveness of earthquake early warning across Europe
}

\author{
Gemma Cremen (1) ${ }^{1 凶}$, Carmine Galasso ${ }^{1,2}$ \& Elisa Zuccolo ${ }^{3}$
}

Here we assess the potential implementation of earthquake early warning (EEW) across Europe, where there is a clear need for measures that mitigate seismic risk. EEW systems consist of seismic networks and mathematical models/algorithms capable of real-time data telemetry that alert stakeholders (e.g., civil-protection authorities, the public) to an earthquake's nucleation seconds before shaking occurs at target sites. During this time, actions can be taken that might decrease detrimental impacts. We investigate distributions of EEW lead times available across various parts of the Euro-Mediterranean region, based on seismicity models and seismic network density. We then determine the potential usefulness of these times for EEW purposes by defining their spatial relationship with population exposure, seismic hazard, and an alert accuracy proxy, using well-established earthquake-engineering tools for measuring the impacts of earthquakes. Our mapped feasibility results show that, under certain conditions, EEW could be effective for some parts of Europe.

\footnotetext{
${ }^{1}$ University College London, London WC1E 6BT, UK. ${ }^{2}$ Scuola Universitaria Superiore (IUSS) Pavia, 27100 Pavia, Italy. ${ }^{3}$ European Centre for Training and

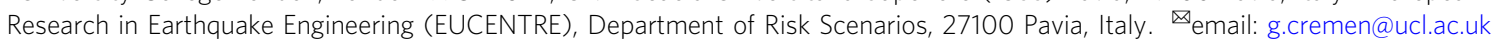


E arthquake early warning (EEW) systems are a relatively recent innovation in earthquake-induced disaster risk reduction and resilience promotion ${ }^{1}$. They consist of seismic sensor networks and mathematical models/algorithms that are designed to process and disseminate real-time information about ongoing earthquakes. The resulting alert messages enable various stakeholders (e.g., individuals, communities, governments, businesses) located at distance to take timely measures for reducing the likelihood of damage or loss before shaking reaches them $^{2}$. Examples of important risk-mitigation actions that can be taken in the short warning time provided by EEW systems (typically seconds) include: (1) Performing "drop, cover and hold on" $(\mathrm{DCHO})^{3}$ or moving to a safer location (either within a building or outside), to avoid injuries; (2) slowing down highspeed trains, to reduce accidents ${ }^{4}$; (3) shutting off gas pipelines, to prevent fires ${ }^{5}$; and (4) switching signals to stop vehicles from entering vulnerable infrastructure components (such as bridges), to avoid fatalities ${ }^{6}$. This list accounts for merely a small number of the vast array of critical applications that can benefit from $\mathrm{EEW}^{7}$, and interested readers are referred to Wald ${ }^{8}$ for a more thorough discussion on this issue.

The process of EEW typically involves up to five main steps: (1) detecting an earthquake; (2) estimating its location; (3) estimating its magnitude; (4) estimating the ground motion at target sites; and (5) using all of the information collected to decide whether (or not) to trigger an alarm. EEW systems may be broadly categorised as "regional", "on-site", or "hybrid", depending on their approach to the first four steps mentioned above. This study exclusively focuses on regional systems, which consist of seismic station networks installed within the expected epicentral/high seismicity area that record the necessary information for estimating the parameters of Steps 1,2 and 3 . The source parameter estimates of Steps 2 and 3 are then used to predict ground shaking (Step 4) at target sites located further away from the fault rupture? .

A number of studies have previously explored the feasibility/ potential of EEW in different parts of the world, including France $^{10}$, Italy ${ }^{11-13}$, Spain ${ }^{14}$, Portugal ${ }^{15}$, Turkey ${ }^{16}$, Japan $^{17}$, California $^{18,19}$, Hawaii ${ }^{20}$, the New Madrid Seismic Zone ${ }^{21}$, and Kyrgyzstan ${ }^{22}$. Regional EEW systems are presently operating in nine countries (including USA, Mexico, and Japan), and have been tested for application in a further $13^{23}$. The only European countries with current government-supported operational EEW systems are Romania ${ }^{24}$ and Turkey ${ }^{25}$ (the Android Earthquake Alert System, which uses Android phones to issue and receive early warnings ${ }^{26-29}$, has also recently been launched in Greece as well as Turkey ${ }^{30}$ ), despite a strong need to develop effective measures for mitigating seismic risk across many parts of the continent ${ }^{31}$; EEW could potentially contribute towards reducing the more than 20 billion of European gross domestic product (GDP) that is affected annually by earthquakes (on average) ${ }^{32}$.

In this study, we investigate the feasibility of EEW application in the Euro-Mediterranean area. In particular, we focus on EEW lead time (i.e., the time between the delivery of an EEW alert and the arrival of shaking at target sites). We compute probabilistic distributions of lead times available for various seismicity scenarios in high-hazard areas across the continent, using a finite-difference travel-time algorithm. We also explicitly quantify the potential effectiveness of these times in the context of EEW, by establishing their spatial relationship with values of proxy measures for earthquake impact and alert accuracy. This work significantly advances the state-of-the-art established by aforementioned studies for a number of reasons. It examines EEW feasibility on a much larger (i.e., continental level) scale by combining EEW methods, models, and tools in a harmonised framework across Europe. Furthermore, we introduce a feasibility metric that enables identification of priority regions for further, more refined EEW feasibility analyses and/or actual investment in EEW systems for targeted end users. This study therefore offers a unique trans-national perspective on the potential of EEW that is relevant for intergovernmental bodies-such as the International Search and Rescue Advisory Group of the United Nations ${ }^{33}$ - who may be interested in leveraging the technology. It also provides valuable new insights on the possible benefits/limitations of EEW for regions (e.g., Iceland and Georgia) that have not recently experienced large earthquakes, but are likely to do so in the future.

\section{Results}

European seismic station density. We conduct a preliminary feasibility study for EEW across the European region, by considering the availability of its most fundamental component, i.e., seismic station networks on which the early seismic signals could be detected/recorded for rapid event characterisation. Figure 1a displays a map of permanent European broadband and strong-motion seismic stations (2377 stations in total). It can be seen from Fig. 1b that $\sim 45 \%$ of interstation distances are less than $20 \mathrm{~km}$ and almost all interstation distances are within $100 \mathrm{~km}$.

Lead-time mapping for high-hazard areas. We now focus on crustal point sources associated with large seismic hazard of engineering significance, which we define as those for which the event with a recurrence interval of 500 years is at least $M_{w} 6.5$ (see Fig. 2a and "Methods" section). For each of these area sources, we calculate potential lead times (i.e., times between

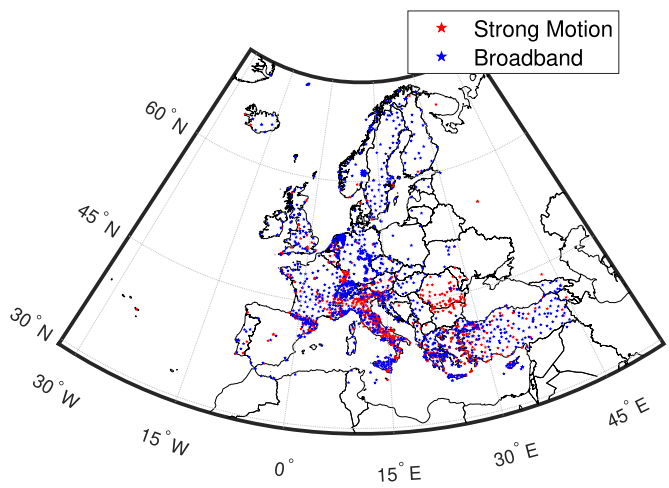

(a)

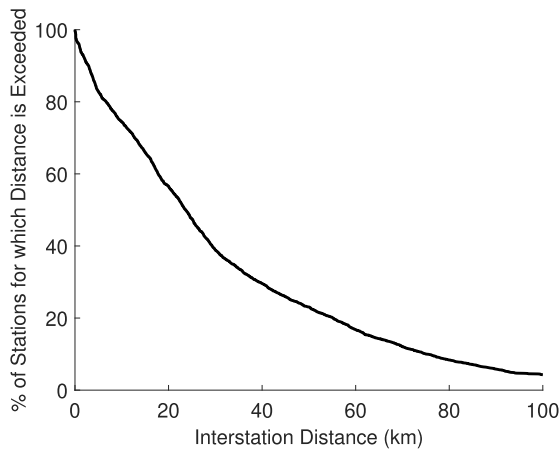

(b)

Fig. 1 Examining seismic station coverage across Europe. a Map of European seismic stations considered and b distribution of interstation distances. 


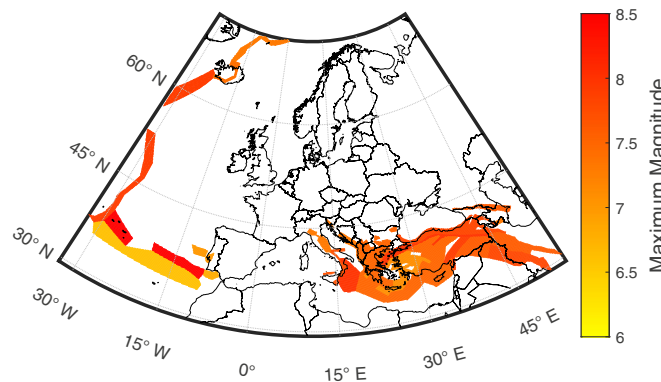

(a)

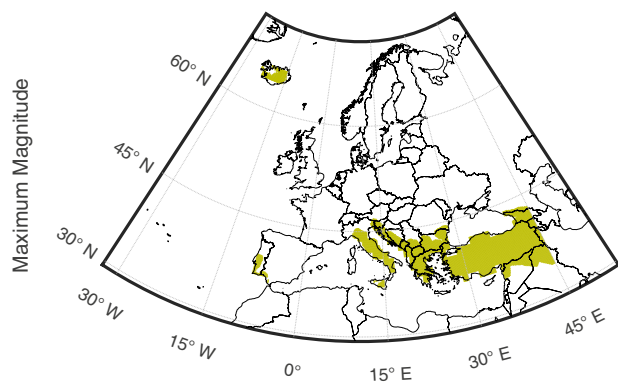

(b)

Fig. 2 Input data for lead-time mapping calculations. a Seismic sources (colour coded in accordance with corresponding modal maximum magnitude values from the seismic hazard model) and $\mathbf{b}$ target sites examined for lead-time calculations.

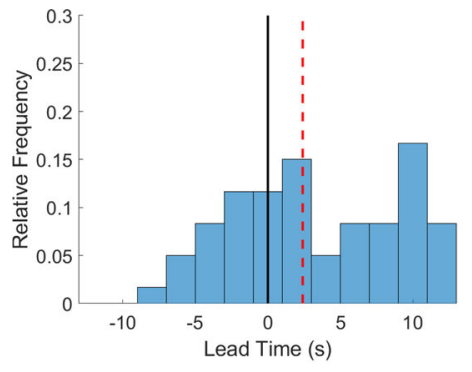

(a)

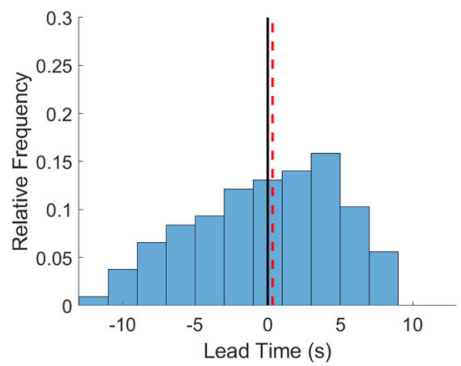

(b)

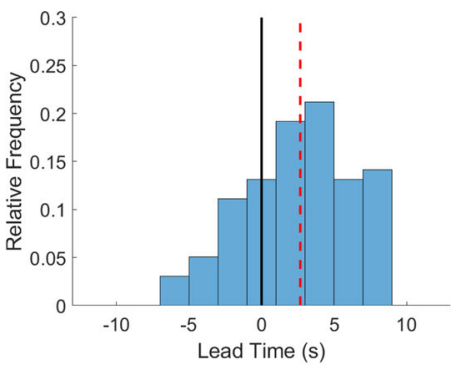

(c)

Fig. 3 Distributions of lead times for target sites in three European cities. a Site in Naples, $\mathbf{b}$ site in Izmir, and $\mathbf{c}$ site in Athens. Note that the red dashed lines indicate the corresponding median lead times and the black solid lines denote the positive lead-time threshold.

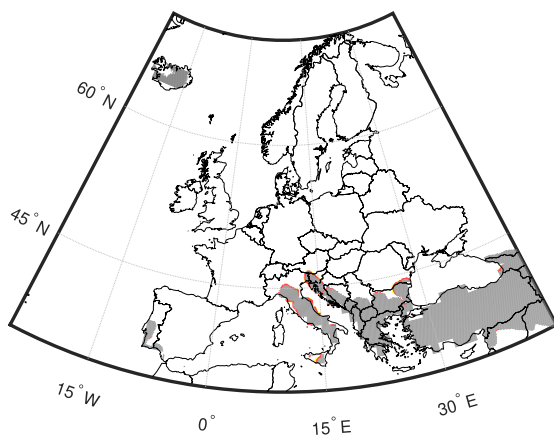

(a)

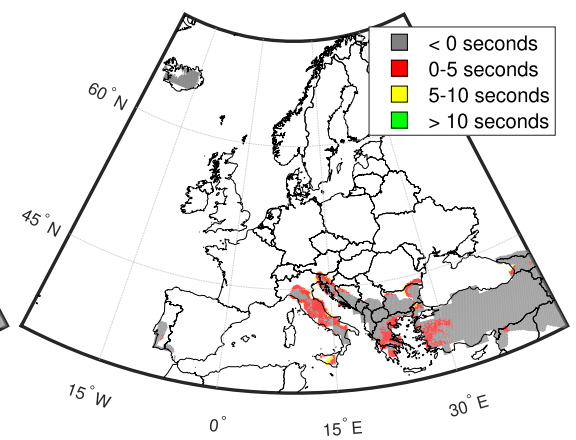

(b)

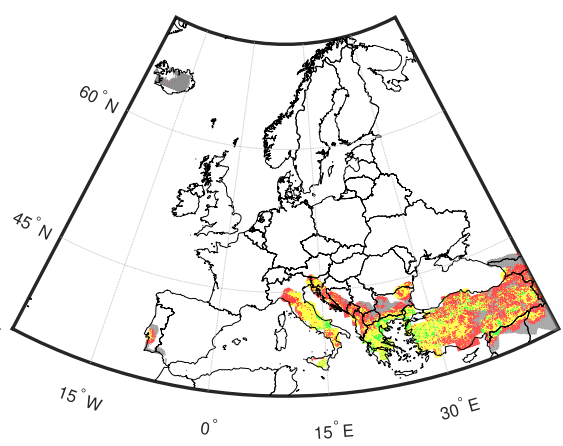

(c)

Fig. 4 Lead-time mapping across all examined target sites. a Minimum lead times, b median lead times, and $\mathbf{c}$ maximum lead times.

EEW alert issuance and the occurrence of shaking) at target sites where the predicted median peak ground acceleration (PGA) associated with 500-year recurrence-interval events exceeds $0.05 \mathrm{~g}$ (see Fig. $2 \mathrm{~b}$ and "Methods" section), which is a commonly used threshold value for moderate earthquake shaking in several engineering applications, including seismic design aimed at life-safety performance ${ }^{34-36}$. These calculations incorporate a magnitude-dependent delay interval that captures the time taken to compute characteristics of the ongoing event and to complete a state-of-the-art real-time data telemetry process (see "Methods" section).

Figure 3 displays histograms of lead times computed at selected target sites in three cities covered by the study area, i.e., Naples, Izmir, and Athens, due to the area sources that comply with the previously outlined criteria. It can be seen that the majority of lead times are positive for the selected sites in Naples and Athens, whereas there is a reasonably even distribution of both positive and negative lead times at the Izmir site. The median lead times for the sites are $2.4 \mathrm{~s}$ (Naples), $0.3 \mathrm{~s}$ (Izmir), and $2.7 \mathrm{~s}$ (Athens), while the standard deviations of the times (in the same order) are 5.8, 4.9, and 3.8; these uncertainties are significant, and are partly explained by the large variation in source-to-site distances for a given site.

Figure 4 contains maps displaying the following three summary statistics for all affected target sites across the continent: (1) lowest computed lead time (i.e., "worst case scenario"), henceforth referred to as "minimum lead time"; (2) median computed lead time; and (3) largest computed lead time (i.e., "best case scenario"), herein referred to as "maximum lead time". Note that negative lead times correspond to blind zones, where no warning is received before shaking occurs. Of all target sites examined, $3 \%$ have positive minimum lead times 
( $<1 \%$ between 5 and $10 \mathrm{~s}$, and the remainder less than $5 \mathrm{~s}$ ); $18 \%$ have positive median lead times ( $1 \%$ between 5 and $10 \mathrm{~s}$, and approximately $16 \%$ less than $5 \mathrm{~s}$ ); and $79 \%$ have positive maximum lead times ( $8 \%$ greater than 10 s, 37\% between 5 and $10 \mathrm{~s}$, and $34 \%$ less than $5 \mathrm{~s}$ ). The maximum lead time achieved across all target sites examined is $17.2 \mathrm{~s}$ (near Sorgun, central Turkey). Target sites with the longest overall median lead times are mainly found in Italy, Greece and Turkey, which are characterised by some of the strongest seismicity in Europe. Target sites with the shortest lead times are located in Iraq, Georgia, and Russia. Table 1 provides a summary of potential

\begin{tabular}{|l}
$\begin{array}{l}\text { Table } 1 \text { Possible risk-mitigation actions that can be taken by } \\
\text { various stakeholders for different lengths of EEW lead time } \\
\text { (adapted from previous works }{ }^{3,15,71-73} \text { ). }\end{array}$ \\
\begin{tabular}{ll} 
Lead time range (s) & Possible actions \\
\hline $0-5$ & - Stopping traffic (i.e., turning lights red) \\
& - Switching on semi-active control systems for \\
& structures \\
& - Performing DCHO \\
& - Stopping elevators at the nearest floor and \\
& opening doors \\
& - Shutting off gas supplies \\
& - Shutting down computers and related \\
& equipment \\
- Evacuating the ground floor of buildings & - Shutting down industrial equipment \\
- Controlling production lines & - Directing traffic away from underpasses \\
& - Stopping surgical procedures \\
& - Removing vehicles from garages
\end{tabular}
\end{tabular}

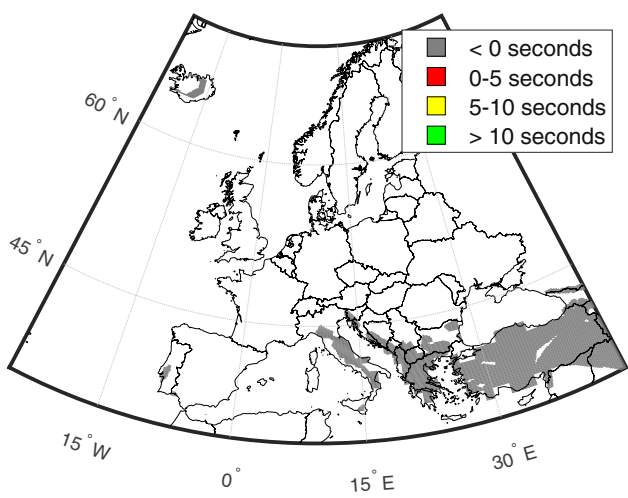

Fig. 5 Lead-time mapping for $M_{w} 5$ events. risk-reducing actions that can be carried out for the various ranges of lead time investigated.

Lead-time sensitivity analyses. We now examine variations in lead times that result from modifying certain assumed inputs of the previous calculations. We first determine lead times for $M_{w} 5$ events at the previously considered point sources, focusing on target sites where these earthquakes produce median predicted PGA greater than $0.05 \mathrm{~g}$ (Fig. 5). Such moderate earthquakes can sometimes have notable consequences ${ }^{8}$, so it is important to understand whether EEW systems could successfully operate for these events. No target sites have positive maximum lead times in this case.

We next determine lead times for the same earthquakes considered in the original calculation that produce a PGA of at least $0.1 \mathrm{~g}$ at a given target site, to account for stakeholders who may only wish to trigger EEW alerts in the case of strong shaking ${ }^{37}$ (see Fig. 6). Less than 1\% of these sites have positive minimum or median lead times (which are all smaller than $5 \mathrm{~s}$, in both cases), and $19 \%$ have positive maximum lead times $(<1 \%$ between 5 and $10 \mathrm{~s}$, and the remainder less than $5 \mathrm{~s}$ ).

Quantifying the effectiveness of computed lead times. We examine the potential usefulness of the original calculated lead times for EEW purposes, by defining their spatial relationship with ambient (average day/night) population distributions and the average seismic intensity across all events with a recurrence interval of 500 years that produce a PGA greater than or equal to $0.05 \mathrm{~g}$ at the affected site (see "Methods" section for details). Population often acts as a proxy for the exposure (i.e., the value at risk) of the built environment/assets in earthquake engineering and risk modelling applications ${ }^{38}$. Seismic intensity describes the effect of earthquake ground shaking on the built environment and communities ${ }^{39,40}$. We use the European Macroseismic Scale (EMS)-98 seismic intensity scale ${ }^{40}$, which is specifically designed for European countries.

Ninety-eight percent of the total ambient population surrounding the examined target sites are affected by average EMS-98 values between V ("Strong"; e.g., top-heavy objects topple over) and VII ("Damaging"; e.g., many objects fall from shelves and there is some wall damage). Figure 7 indicates that $\sim 30 \%$ of the ambient population are affected by EMS-98 values between $\mathrm{V}$ and VI ("Slightly damaging"; e.g., objects fall from walls and there is some damage to plaster), while $\sim 68 \%$ are affected by values between VI and VII. Five percent of the ambient population affected by average intensities between $\mathrm{V}$ and VI have maximum lead times greater than $10 \mathrm{~s}$, while $22 \%$ have negative maximum lead times (i.e., they are located in the "blind zone"). Thirty-two percent of this population have positive median lead times, and

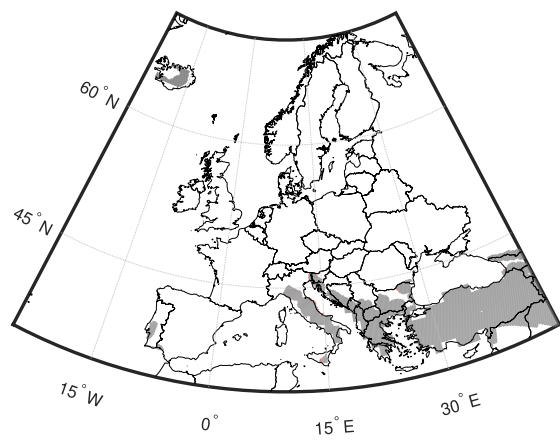

(a)

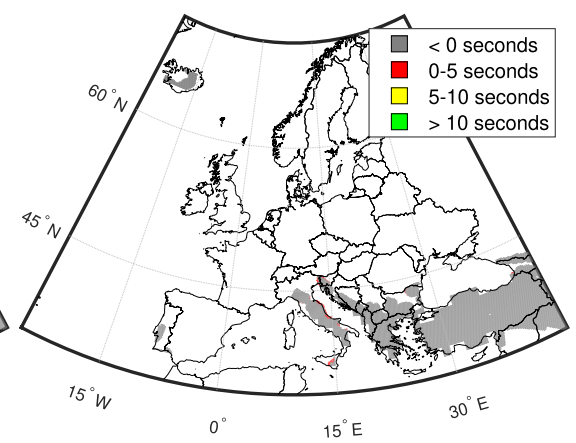

(b)

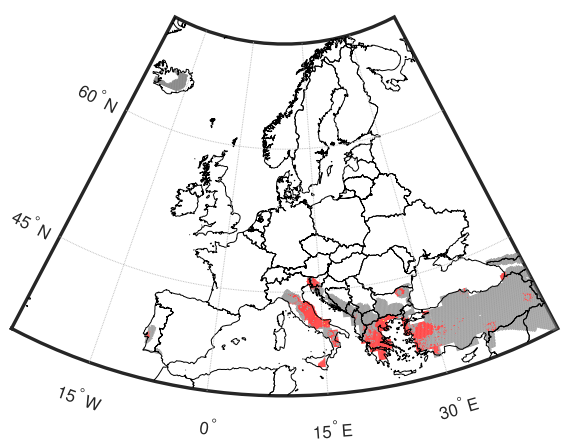

(c)

Fig. 6 Lead-time mapping for a $\mathbf{0 . 1} \mathbf{g}$ EEW alert threshold. a Minimum lead times, $\mathbf{b}$ median lead times, and $\mathbf{c}$ maximum lead times. 


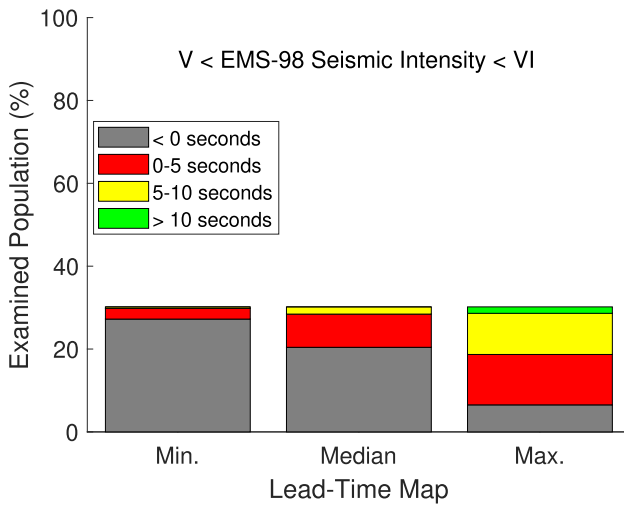

(a)

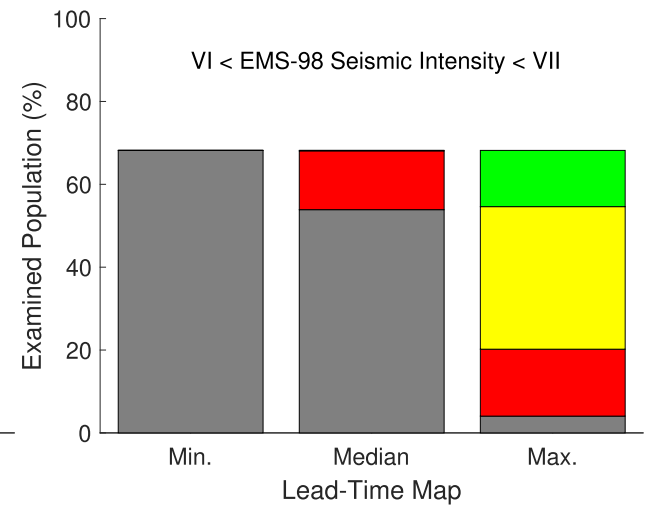

(b)

Fig. 7 Examining the potential effectiveness of calculated lead times for EEW. Average EMS-98 macroseismic intensities experienced by the affected ambient population during events with a recurrence interval of 500 years that resulted in at least $0.05 \mathrm{~g}$ PGA at the associated target site, categorised by the corresponding times of the maps presented in Fig. 4. Note that seismic intensities V, VI, and VII denote "strong", "slightly damaging", and "damaging" events, respectively.

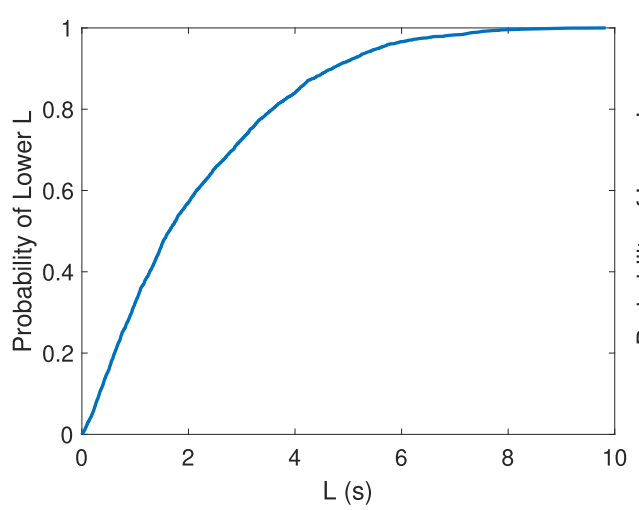

(a)

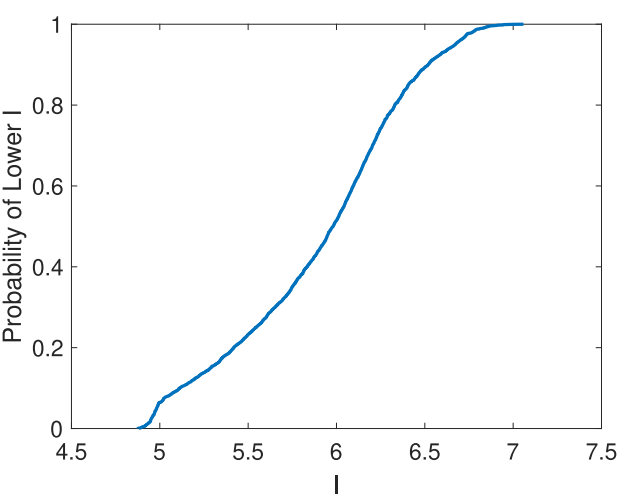

(b)

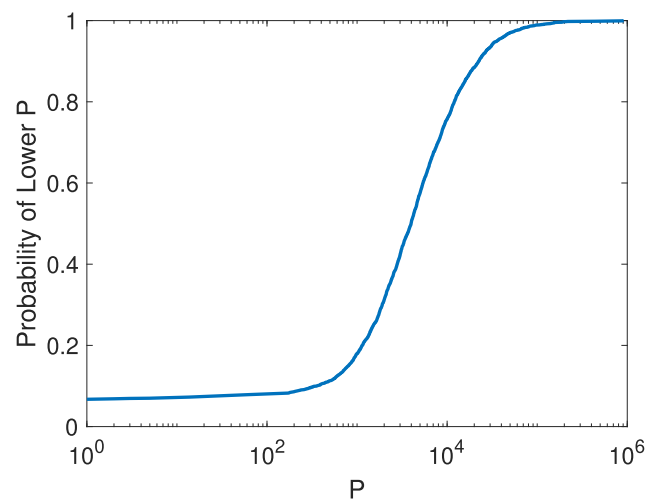

(c)

Fig. 8 Deriving the EEW relative feasibility index. Empirical cumulative distribution functions of a median lead time $(L)$, $\mathbf{b}$ average seismic intensity $(I)$, and $\mathbf{c}$ ambient population $(P)$.

$10 \%$ have positive minimum lead times. Twenty percent of the ambient population affected by average intensities between VI and VII have maximum lead times greater than $10 \mathrm{~s}$, while $6 \%$ are located in the "blind zone". Twenty-one percent of this population have positive median lead times, and less than $1 \%$ have positive minimum lead times.

EEW feasibility calculation. We combine estimates of median lead time $(L)$, average seismic intensity $(I)$, and affected ambient population $(P)$ into a single metric of EEW feasibility, termed the EEW relative feasibility index, which ranges from 0 to 1 (see Eq. (3) of
"Methods" section for details). Higher values of this index correspond to key characteristics that maximise the effectiveness of an EEW system ${ }^{41}$, i.e.,: (1) longer lead times; (2) higher potential for shaking causing losses that can be avoided with EEW; and (3) larger affected populations. They therefore indicate greater EEW feasibility for a given target site. For context, Fig. 8 provides the empirical cumulative distribution functions (ECDF) of $L, P$, and $I$ that are used to derive the index. Note that the purpose of the index is to identify the most feasible regions for EEW, regardless of the extent to which their feasibility differs to that of less feasible regions (and therefore the steepness of the underlying ECDF). This approach is 


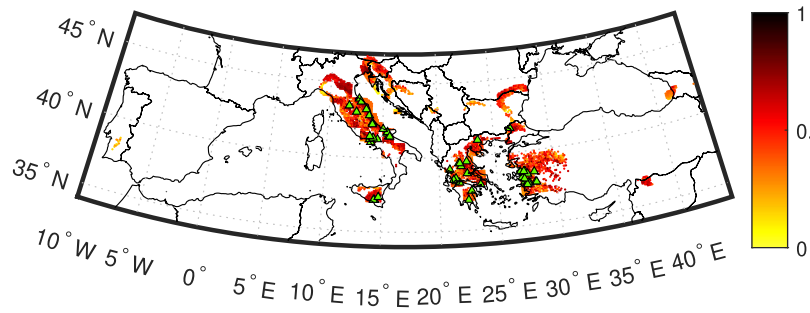

(a)

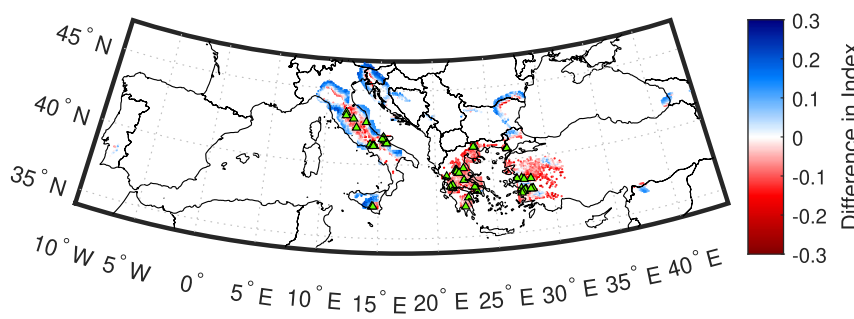

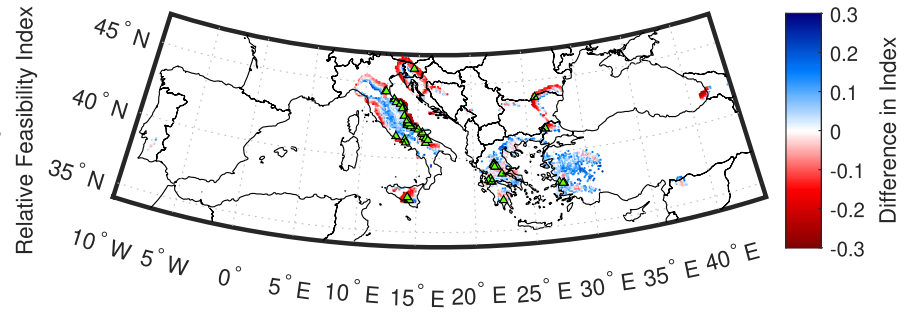

(b)

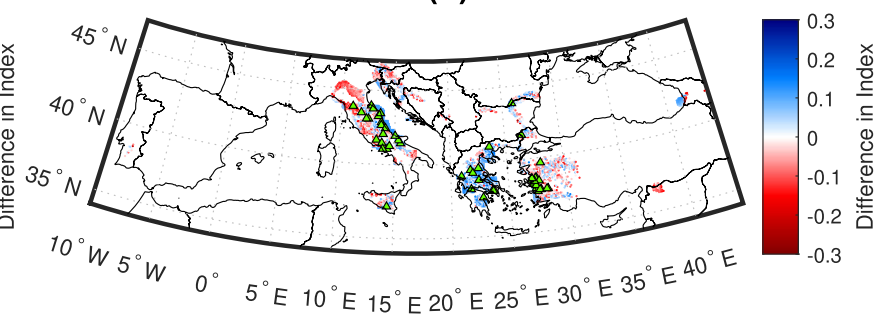

(c)

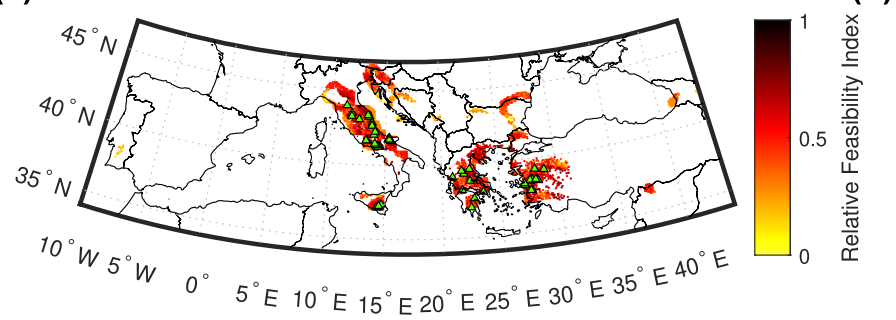

(e)

Fig. 9 Relative feasibility index mapping across examined target sites. Indices for a the case in which lead time, intensity, and population are equally weighted by a stakeholder, as well as differences for cases in which $\mathbf{b}$ lead time, c seismic intensity, and $\mathbf{d}$ population are respectively weighted three times more than both other variables. Also shown are e equally weighted indices modified in line with the relative number of correctly issued alerts (for a $0.05 \mathrm{~g}$ alert threshold $)^{19}$. Note that for $\mathbf{b}-\mathbf{d}$, red colours indicate an increase in the index relative to $\mathbf{a}$ and blue colours indicate a relative decrease. Green triangles indicate target sites with one of the 50 largest indices for each case.

consistent with many multi-criteria decision-making tools, including the Technique for Order of Preference by Similarity to Ideal Solution $^{42}$ and multi-attribute utility theory ${ }^{43}$.

It can be seen from Eq. (3) that the index accommodates a userdefined weight for each measurement, to account for stakeholder preferences and priorities towards each feature of feasibility. Figure 9 includes EEW Relative Feasibility Index mapping of all target sites with positive median lead time, for the equally weighted case (i.e., $w_{P}=w_{I}=w_{L}=0.333$ ) and for cases where one variable (e.g., lead time) is weighted three times more than the other two (e.g., $w_{L}=0.6$, and $\left.w_{P}=w_{I}=0.2\right)$. Note that a site associated with the 10 th percentile value of positive $L$, the 20th percentile value of $I$, and the 40th percentile value of $P$ would yield the following relative feasibility indices for the different examined weighting strategies: $0.23\left(w_{P}=w_{I}=w_{L}=0.333\right), 0.18\left(w_{L}=0.6\right.$, and $\left.w_{P}=w_{I}=0.2\right)$, $0.22\left(w_{I}=0.6\right.$, and $\left.w_{L}=w_{P}=0.2\right)$, and $0.3 \quad\left(w_{P}=0.6\right.$, and $\left.w_{L}=w_{I}=0.2\right)$. In contrast, for the same respective weighting strategies, a site associated with the 90th percentile value of positive $L$, the 80th percentile value of $I$, and the 60 th percentile value of $P$ would produce relative feasibility indices of $0.77,0.82,0.78$, and 0.7 . Also highlighted in each subplot of Fig. 9 are the fifty target sites with the largest index values for the corresponding case. For all cases, the countries containing all (or almost all) of the sites with the fifty largest feasibility indices are Italy, Turkey, and Greece. However, both the locations and the number of sites per country differ between cases. Relative to the equally weighted case, target sites with the largest increase and decrease in feasibility index for the case where lead time is the most weighted variable are located in Georgia and Turkey respectively, target sites with the largest increase and decrease in this value for the case where seismic intensity is the most weighted variable are located in Greece and Georgia respectively, and target sites with the largest increase and decrease in feasibility index for the case where population is the most weighted variable are respectively located in Italy and Greece.

Finally, we investigate the impact of alert accuracy (i.e., the ability of the system not to miss alarms or provide false warnings) on EEW feasibility. We specifically adopt the approach of Minson et al. ${ }^{19}$, which examines the forecasting capability of EEW in terms of ground motion prediction accuracy for a set of known source parameters. We randomly sample PGA values at each site for a series of earthquakes across nearby sources, assuming that an alert is issued if the corresponding median predicted PGA exceeds $0.05 \mathrm{~g}$. The relative feasibility indices of Fig. 9a are then modified in line with the relative proportion of correctly issued alerts to produce Fig. 9e; see Eqs. (4) and (5) of "Methods" section for details. Alert accuracy causes the largest feasibility increase and decrease at sites in Slovenia and Romania, respectively. However, Turkey, Italy, and Greece still maintain the largest feasibility. Although alert accuracy is highly dependent on the selected threshold ${ }^{19}$, it is important to note that the top three countries for EEW feasibility do not change if the triggering PGA 
is instead set to $0.02 \mathrm{~g}, 0.10 \mathrm{~g}$, or $0.20 \mathrm{~g}$, i.e., the three exceedance values examined in Minson et al. ${ }^{19}$ for California.

\section{Discussion}

This study has examined the relative feasibility of EEW for Europe. We initially analysed the density of seismic station coverage across the continent. We found that almost half of interstation distances are less than $20 \mathrm{~km}$, which corresponds with the distance limit recommended for optimum EEW performance in previous work ${ }^{41}$. These findings are a preliminary signal that there is some potential for operational EEW across the continent. Our detailed relative feasibility analysis focused on EuroMediterranean regions affected by significant seismic hazard. This indicated that the viability of EEW in Europe is highly dependent on the magnitude of the ongoing event and the threshold PGA at which an EEW alert is issued at a target site. For example, it was determined that $45 \%$ of the examined target sites could benefit from lead times in a "best case scenario" that are long enough to accommodate some important risk intervention actions-such as the shutting off of gas supplies and the evacuation of ground floors-if the magnitude is large (i.e., at least $\left.M_{w} 6.5\right)$ and the threshold for EEW alert triggering is $0.05 \mathrm{~g}$, but this proportion reduces to less than $1 \%$ if the triggering PGA is instead set to $0.1 \mathrm{~g}$, and no sites benefit from these long lead times for a $M_{w} 5$ event. Eighteen percent of all examined target sites have a $50 \%$ chance of receiving an EEW alert that allows time for at least some automatic actions (such as the switching of a traffic light), for a large magnitude event and a $0.05 \mathrm{~g}$ triggering threshold, but no (or almost no) sites have sufficient median lead time to facilitate these types of measures if the magnitude is reduced to $M_{w} 5$, and/or the triggering threshold is instead set to $0.1 \mathrm{~g}$. In a "worst case scenario", large magnitude earthquakes and a $0.05 \mathrm{~g}$ triggering threshold are the only examined conditions that produce some positive EEW lead time at more than $0.25 \%$ of sites. In summary, the ultimate success of European EEW (from a functionality standpoint) will be dictated by the practical conditions of its usage and the underlying seismotectonic setting(s). We found that the longest overall lead times mainly occur at sites in Italy, Greece, and Turkey. Areas associated with the shortest overall median lead times, and therefore where the feasibility of EEW could be improved through increased seismic station density, are northern Iraq, north-western Georgia, and southern Russia.

We further contextualised the significance of the lead times by combining them with spatial distributions of two proxies often used to measure the effects of an earthquake in earthquake engineering (i.e., population and seismic intensity). We found that almost all (i.e., $\sim 98 \%$ ) of the affected ambient population are exposed to average seismic intensities from large earthquakes at nearby seismic sources that at least result in some falling objects. This suggests, for example, that EEW could help to protect against injuries through $\mathrm{DCHO}$, evacuation or other means. Fifteen percent of these people have greater than $10 \mathrm{~s}$ of lead time in a "best case scenario", which enables them to carry out major preventive actions, such as the shutting down of industrial equipment. A notable amount of the population $(25 \%)$ have positive lead times from events at $50 \%$ of relevant sources, while $\sim 4 \%$ have some lead time in a "worst case scenario". These findings indicate that European EEW could be useful for mitigating the effects of large events on exposed populations.

Finally, we translated the aforementioned features (i.e., (1) lead time; (2) average seismic intensity from large earthquakes at nearby sources; and (3) ambient population affected) into an indicator for measuring relative EEW feasibility at a given target site that also accounts for stakeholder-specific preferences (weights). While there was some variation in the results obtained for different weighting strategies, all maps indicated that Turkey, Italy, and Greece contain all (or almost all) of the target sites with the highest relative EEW feasibility. We additionally examined the impact of alert accuracy on the equally weighted relative feasibility map, and found that the same three countries still demonstrated the largest relative feasibility, regardless of the alert threshold considered ${ }^{19}$

In particular, the computed relative feasibility indices suggest that an expansion of permanent EEW efforts in Turkey beyond Istanbul (by upgrading the hardware and software of existing strong-motion/broadband stations and networks for real-time data processing and telemetry capabilities) could be appropriate, supporting the recently launched Android Earthquake Alert System in the country. The promising results of the relative feasibility mapping for Italy and Greece are particularly notable, since neither has a current permanently operational EEW system (although Greece is now also benefiting from the Android Earthquake Alert System). We ultimately conclude that this work provides evidence to suggest that some parts of Europe could benefit from EEW as a helpful supplemental tool for supporting earthquake-related disaster risk reduction ${ }^{8}$ but the extent of its effectiveness would be highly sensitive to the size of targeted events and the threshold at which an alert is triggered.

It is important to note that there are some limitations/simplifying assumptions associated with this work that warrant comment. Firstly, we leveraged an international database to obtain details on seismic stations across the continent (see "Methods" section). This approach may not have completely captured all stations across Europe and our calculations may have underestimated actual lead times in some cases; for the actual design/implementation of EEW systems in any region, an exhaustive search of local databases would be critical to produce detailed and accurate lead-time estimates. However, exploiting local seismic station databases in this study could have created an unfair bias against countries/regions that do not provide/store this type of information and may have introduced discrepancies in the quality of information used. In fact, all of the data employed in this work (including those related to seismic hazard and population) are from consistent and open high-level sources to reflect the broad geographical extent of the study and ensure the results are fully replicable. Secondly, it is assumed that the considered seismic stations are (or could be) capable of being used for early warning purposes (i.e., they have or could have adequate data acquisition/transmission systems, real-time communication capability, robust dissemination methods, power supply systems, etc. ${ }^{10,20}$ ), which may be an over-simplification ${ }^{1}$. The times considered in Table 1 for taking prescribed actions during an EEW alert may be longer in practical cases, given that human reaction latencies have not yet been well-established in this context ${ }^{8}$. We used a 1-D velocity model in the travel-time algorithm, which does not capture lateral variations in the earth's structure. Our detailed EEW feasibility analysis only accounted for crustal seismic sources, thereby yielding conservative lead times for target sites that would additionally be affected by the deeper seismicity of subduction zones in the Central and Eastern Mediterranean Sea. It therefore also neglected the seismicity of the Vrancea region in Romania ${ }^{44}$, which has significant associated hazard ${ }^{45}$; examination of this region is not crucial in the context of our study however, given that it already has an operational EEW system ${ }^{24,46}$. In any case, preliminary investigations indicate that the conclusions of the relative feasibility mapping do not strongly depend on the accuracy of the leadtime calculations; using interpolated values of interstation distance (see "Methods" section for details on this metric) as a 
proxy for lead times in the feasibility index (where smaller distances indicate higher relative feasibility, in line with the findings of Kuyuk and Allen ${ }^{41}$ ) still produces the largest index values in Turkey, Italy and Greece. To maintain a uniform approach for the entire examined region, the considered seismicity scenarios were defined using an area source model (see "Methods" section), which assumes a uniform occurrence of earthquakes as point sources; thus, the resulting calculations of hazard near faults (large seismogenic sources) may not be completely realistic ${ }^{47}$. Our approach to quantifying alert accuracy only considered the variability of a ground motion model $(\mathrm{GMM})^{19}$. Precisely characterising warning accuracy would involve more detailed analysis with the specific algorithms of operational EEW platforms, including the quantification and propagation of uncertainties at each step of the calculations. This type of examination was carried out for select testbed sites across Europe in previous studies by the same authors ${ }^{48,49}$. It is outside the scope of this paper, given the continent-wide extent of the study (i.e., it is likely that different EEW algorithms would suit different regions) and the fact that this work is foremost an investigation of feasibility. Finally, we did not consider the economic value of EEW, i.e., the costs required to build and maintain EEW systems compared to the monetary savings they provide through avoided damage ${ }^{50}$. Despite these constraints, this study nevertheless represents a first attempt to comprehensively quantify potential EEW effectiveness on a continental scale and to identify priority regions for more detailed EEW feasibility analyses/investment in EEW implementation.

\section{Methods}

\section{Data descriptions}

Seismic stations. We use current seismic station locations in this work (and thus account for the geometrical characteristics of the network, assuming that necessary hardware/software upgrades for EEW are possible), in line with previous studies that have examined EEW feasibility ${ }^{12,51}$. Station coordinates are obtained using the Incorporated Research Institutions for Seismology (IRIS) Google map (GMAP) station mapping service (http://ds.iris.edu/gmap/). We consider all permanent strong-motion and broadband stations between $-26^{\circ}$ and $45^{\circ}$ longitude, and $34^{\circ}$ and $72^{\circ}$ latitude.

Seismic sources. We use the area source model of the 2013 European Seismic Hazard Model, which accounts for crustal seismicity with depth $\leq 40 \mathrm{~km}^{52,53}$. To define seismic sources, we discretise the model into $0.1^{\circ} \times 0.1^{\circ}$ cells. We specifically make use of the depth, maximum magnitude, style-of-faulting, and Gutenberg-Richter $a, b$ parameters from the model. Each source is assumed to be characterised by all parameter values associated with the corresponding area source zone. We use the values associated with the highest weight in the logic tree, where applicable, and average depth values for stable continental regions. The moment magnitude of the event with a recurrence interval of 500 years for a given source $(\mathrm{m})$ satisfies the following equation:

$$
\lambda_{m}-\lambda_{m_{\max }}=0.002
$$

where $\lambda_{m}$ is the annual rate of earthquakes with magnitude greater than $m$, according to the Gutenberg-Richter magnitude-frequency relationship ${ }^{54}$, and $m_{\max }$ is the modal maximum magnitude for the given source. We focus on the 37,869 sources for which $m \geq 6.5$. The catalogue generated to quantify alert accuracy consists of 1,000 earthquakes per source that are Gutenberg-Richter distributed and have uniform annual rates of occurrence (from Eq. (1)) between 0 and 1. Predictions of PGA and peak ground velocity (PGV) associated with all events are computed/sampled using the Joyner-Boore distance version of the Akkar et al. $\mathrm{GMM}^{55}$. (We compute Joyner-Boore distances from epicentral distances, using the adjustment factors of Thompson and Worden ${ }^{56}$ for the style-of-faulting and tectonic setting of the associated seismic source). The site amplification input to the GMM is the shear wave velocity in the uppermost $30 \mathrm{~m}$, which is estimated at each target site from a topographic slope map ${ }^{57}$.

Target sites. Target sites are equivalent to all land-based seismic sources (i.e. those without a water layer at or above zero-elevation in the corresponding 1-D velocity profile; see "Travel times" section), located within the same coordinate boundaries as the seismic stations.

Seismic station density. Interstation distance for a given seismic station is the average distance to the closest three stations.

\section{Lead-time modelling}

Travel times. We use the travel-time algorithm of the open-source NonLinLoc software package (http://alomax.free.fr/nlloc/) ${ }^{58}$. This method calculates first arrival travel times for the nodes of a spatial grid using the Eikonal finitedifference scheme of Podvin and Lecomte ${ }^{59}$, which is an approximation of Huygen's principle ${ }^{60}$. We use a grid spacing of $10 \mathrm{~km}$ in all directions, and incorporate a normally distributed zero-mean timing error with 0.2 variance. Both source-to-site and source-to-station travel times are calculated using 1-D velocity profiles from the CRUST 1.0 velocity $\operatorname{model}^{61}$, at the location of the target site. Note that travel times are computed to zero-elevation at the target site.

Lead-time calculation. The lead time (in seconds) for target site $j$ due to an event at a given seismic source $a$ is calculated as follows:

$$
\mathrm{LT}_{j}=\mathrm{TT}_{a, j}^{s}-\mathrm{TT}_{a, s t_{3}}^{p}-\delta_{m}-\delta_{t}
$$

where $\mathrm{TT}_{a, j}^{s}$ is the S-wave arrival time at $j$, and $\mathrm{TT}_{a, s t_{3}}^{p}$ is the $\mathrm{P}$-wave arrival time at the third closest station to the source. We account for the triggering of three stations, as it is the minimum required for many popular regional EEW algorithms to report reliable source parameter estimates ${ }^{62-64} . \delta_{m}$ represents the time required to compute the magnitude of the ongoing event, and is assumed to equal $3 \mathrm{~s}$ for $M_{w}<6.5$, $4 \mathrm{~s}$ for $6.5 \leq M_{w}<7,12 \mathrm{~s}$ for $7 \leq M_{w}<7.5$, and $20 \mathrm{~s}$ for $M_{w} \geq 7.5^{65}$ The value of $\delta_{m}$ used for a given area source is based on the magnitude of the event with a recurrence interval of 500 years (except when $M_{w} 5$ events are examined, in which case $\delta_{m}$ is uniformly set to $3 \mathrm{~s}$ ). Note that the relatively large $\delta_{m}$ values for magnitudes greater than or equal to 7 require an implicit assumption that the underlying EEW algorithm is capable of filtering out polluting $\mathrm{S}$-waves from long $\mathrm{P}$-wave windows. The validity of this assumption does not significantly affect the outcomes of the study, however; removing from the analyses sources for which $\delta_{m} \geq 12$ and the nearest station is less than $80 \mathrm{~km}$ does not change the conclusions of the work. $\delta_{t}$ captures data telemetry delays, which are idealistically assumed to comprise $1 \mathrm{~s}$ for data transmission and $1 \mathrm{~s}$ for issuing the warning message ${ }^{66-68}$.

Lead-time effectiveness modelling. Seismic intensities are calculated from the bilinear equations for EMS-98 macroseismic intensity developed by Masi et al. ${ }^{69}$, using median PGV predictions (see "Seismic sources" section). Population data are obtained from the 2018 LandScan database ${ }^{70}$, which contains global ambient population distributions at a $30^{\prime \prime} \times 30^{\prime \prime}$ spatial resolution. Each target site is assigned the aggregated population across all LandScan grid points closest to it.

EEW feasibility modelling. The relative feasibility index measure for target site $j$ $\left(\mathrm{RF}_{j}\right)$ considers its associated values of median lead-time $(L)$, average seismic intensity $(I)$, and ambient population $(P)$ :

$$
\mathrm{RF}_{j}=\mathrm{F}_{\mathrm{L}}\left(l_{j}\right) \times w_{L}+\mathrm{F}_{\mathrm{I}}\left(i_{j}\right) \times w_{I}+\mathrm{F}_{\mathrm{P}}\left(p_{j}\right) \times w_{P}
$$

where $\mathrm{F}_{\mathrm{X}}\left(x_{k}\right)$ is the ECDF of $X$ (across all examined target sites with positive median lead time) evaluated at target site $k$, and $w_{X}$ is the stakeholder-assigned weight for $X$ (note that $w_{P}+w_{I}+w_{L}=1$ ). Each $\mathrm{F}_{\mathrm{X}}($.$) function ranks the sites$ based on the underlying metric (i.e., $L, I$ or $P$ ). The maximum theoretical value of $\mathrm{RF}_{j}$ is 1 , which is achieved if site $j$ is simultaneously associated with the longest median lead time, the highest average seismic intensity, and the largest ambient population.

$\mathrm{RF}_{j}$ is modified to account for alert accuracy (CA), as follows:

$$
\mathrm{RF}_{j, \text { alert }}=\mathrm{RF}_{j}+\mathrm{F}_{\mathrm{CA}}\left(c a_{j}\right) \times w_{C A}
$$

where $c a_{j}$ is the proportion of correct alerts at site $j$, calculated according to:

$$
c a_{j}=\frac{n_{c a, j}}{n_{j}}
$$

$n_{j}$ is the total number of catalogue earthquakes examined for $j$ (see "Seismic sources" section), which is all events from sources considered in the lead-time calculation that yield a predicted median PGA at the site of at least $0.001 \mathrm{~g}$ and result in either a false alert, a missed alert, or a correct alert $\left(n_{c a, j}\right)$-we ignore cases where the system correctly issues no alert, in line with Minson et al. ${ }^{19}$ and $w_{P}+w_{I}+w_{L}+w_{C A}=1$. A false alert occurs if the predicted median PGA exceeds the threshold and the actual (randomly simulated) PGA does not, while a missed alert occurs in the opposite case. All other considered combinations of predicted median and actual ground shaking produce a correct alert.

\section{Data availability}

The seismic station location data are available from the IRIS Google map (GMAP) station mapping service (http://ds.iris.edu/gmap/). The seismic source data and general target site locations are from the 2013 European Seismic Hazard Model ${ }^{52,53}$. The estimates of shear wave velocity in the uppermost $30 \mathrm{~m}$ are available in the database of Wald and Allen ${ }^{57}$. The velocity profiles are provided in the CRUST 1.0 dataset ${ }^{61}$. The population data are available in the 2018 Landscan database ${ }^{70}$. 


\section{Code availability}

Code used in this research is available on Github at: https:/github.com/gcrem/ EEW_LEADTIME_EUROPE.

Received: 21 October 2020; Accepted: 23 November 2021;

Published online: 08 February 2022

\section{References}

1. Allen, R. M. \& Melgar, D. Earthquake early warning: advances, scientific challenges, and societal needs. Ann. Rev. Earth Planet Sci. 47 https://doi.org/ 10.1146/annurev-earth-053018 (2019).

2. UNISDR. 2009 UNISDR Terminology on Disaster Risk Reduction. Tech. Rep. (UN International Strategy for Disaster Risk Reduction (UNISDR), Geneva, Switzerland, 2009)

3. Porter, K. A. How Many Injuries can be Avoided through Earthquake Early Warning and Drop, Cover, and Hold On? Tech. Rep. (Structural Engineering and Structural Mechanics Program, Department of Civil Environmental and Architectural Engineering, University of Colorado, Boulder, Colorado, 2016).

4. Fabozzi, S., Bilotta, E., Picozzi, M. \& Zollo, A. Feasibility study of a loss-driven earthquake early warning and rapid response systems for tunnels of the Italian high-speed railway network. Soil Dyn. Earthquake Eng. 112, 232-242 (2018).

5. Gasparini, P., Manfredi, G. \& Zschau, J. Earthquake early warning as a tool for improving society's resilience and crisis response. Soil Dyn. Earthquake Eng. https://doi.org/10.1016/j.soildyn.2010.09.004 (2011).

6. Le Guenan, T. et al. Accounting for end-user preferences in earthquake early warning systems. Bull. Earthquake Eng. 14, 297-319 (2016).

7. Velazquez, O., Pescaroli, G., Cremen, G. \& Galasso, C. A review of the technical and socio-organizational components of earthquake early warning systems. Front. Earth Sci. 8, 445 (2020).

8. Wald, D. J. Practical limitations of earthquake early warning. Earthquake Spectra 36 https://doi.org/10.1177/8755293020911388 (2020).

9. Satriano, C., Wu, Y. M., Zollo, A. \& Kanamori, H. Earthquake early warning: concepts, methods and physical grounds. Soil Dyn. Earthquake Eng. 31, 106-118 (2011).

10. Auclair, S., Goula, X., Jara, J. A. \& Colom, Y. Feasibility and interest in earthquake early warning systems for areas of moderate seismicity: case study for the Pyrenees. Pure Appl. Geophys. 172, 2449-2465 (2015).

11. Picozzi, M. et al. Exploring the feasibility of a nationwide earthquake early warning system in Italy. J. Geophys. Res. Solid Earth. 120, 2446-2465 (2015).

12. Picozzi, M. et al. Earthquake early warning system for schools: a feasibility study in southern Italy. Seismol. Res. Lett. 86, 398-412 (2015).

13. Emolo, A. et al. Earthquake early warning feasibility in the Campania region (southern Italy) and demonstration system for public school buildings. Bull. Earthquake Eng. 14, 2513-2529 (2016).

14. Pazos, A. et al. A regional approach for earthquake early warning in South West Iberia: a feasibility study. Bull. Seismol. Soci. Am. 105, 560-567 (2015).

15. Oliveira, C. S., Mota de Sá, F., Lopes, M., Ferreira, M. A. \& Pais, I. Early warning systems: feasibility and end-users' point of view. Pure Appl. Geophys. 172, 2353-2370 (2015).

16. Oth, A., Böse, M., Wenzel, F., Köhler, N. \& Erdik, M. Evaluation and optimization of seismic networks and algorithms for earthquake early warning-the case of Istanbul (Turkey). J. Geophys. Res. 115, 10311 (2010).

17. Meier, M. A. et al. How often can earthquake early warning systems alert sites with high-intensity ground motion? J. Geophys. Res. Solid Earth 125 https:// doi.org/10.1029/2019JB017718 (2020).

18. Minson, S. E., Meier, M.-A., Baltay, A. S., Hanks, T. C. \& Cochran, E. S. The limits of earthquake early warning: timeliness of ground motion estimates. Sci. Adv. 4, 2478 (2018).

19. Minson, S. E. et al. The limits of earthquake early warning accuracy and best alerting strategy. Sci. Rep. 9 https://doi.org/10.1038/s41598-019-39384-y (2019).

20. Thelen, W. A., Hotovec-Ellis, A. J. \& Bodin, P. Feasibility Study of Earthquake Early Warning (EEW) in Hawaii. Open-File Report 2016-1172. Tech. Rep. (U.S. Geological Survey, 2016).

21. Ogweno, L. P., Withers, M. M. \& Cramer, C. H. Earthquake early warning feasibility study for the New Madrid seismic zone. Seismol. Res. Lett. 90, 1377-1392 (2019).

22. Picozzi, M., Bindi, D., Pittore, M., Kieling, K. \& Parolai, S. Real-time risk assessment in seismic early warning and rapid response: a feasibility study in Bishkek (Kyrgyzstan). J. Seismol. 17, 485-505 (2013).

23. Cremen, G. \& Galasso, C. Earthquake early warning: recent advances and perspectives. Earth Sci. Revi. 205, 103184 (2020).

24. Mârmureanu, A., Ionescu, C. \& Cioflan, C. O. Advanced real-time acquisition of the Vrancea earthquake early warning system. Soil Dyn. Earthquake Eng. https://doi.org/10.1016/j.soildyn.2010.10.002 (2011).
25. Alcik, H., Ozel, O., Apaydin, N. \& Erdik, M. A study on warning algorithms for Istanbul earthquake early warning system. Geophys. Res. Lett. 36 https:// doi.org/10.1029/2008GL036659 (2009).

26. Allen, R. M., Kong, Q. \& Martin-Short, R. The myshake platform: a global vision for earthquake early warning. Pure Appl. Geophys. 177, 1699-1712 (2020).

27. Kong, Q., Martin-Short, R. \& Allen, R. M. Toward global earthquake early warning with the myshake smartphone seismic network, part 1 : Simulation platform and detection algorithm. Seismol. Res. Lett. 91, 2206-2217 (2020).

28. Kong, Q., Martin-Short, R. \& Allen, R. M. Toward global earthquake early warning with the myshake smartphone seismic network, part 2: Understanding myshake performance around the world. Seismol. Res. Lett. 91 2218-2233 (2020)

29. Cardno, C. A. Android phones now offer earthquake detection, alerts. Civil Engin. Magazine Archive 90, 34-36 (2020).

30. Lee, F. 6 new features on android this summer. The Key Word (2021).

31. Crowley, H. et al. Towards a uniform earthquake risk model for Europe. In 16th European Conference on Earthquake Engineering (Thessaloniki, 2018).

32. World Bank. Europe and Central Asia-Country Risk Profiles for Floods and Earthquakes (English). Tech. Rep. (World Bank Group, Washington, DC, 2017).

33. United Nations Office for the Coordination of Humanitarian Affairs. INSARAG Guidelines V1, Policy. Tech. Rep. (United Nations, 2015).

34. Bolt, B. Duration of strong motion. In 5th World Conference on Earthquake Engineering (Rome, 1973).

35. Vanmarcke And, E. H. \& Lai, S.-S. P. Strong-motion duration and RMS amplitude of earthquake records. Bull. Seismol. Soc. Am. 70, 1293-1307 (1980).

36. Elghazouli, A. Y. Seismic Design of Buildings to Eurocode 8 (CRC Press, Taylor \& Francis Group, 2016).

37. Worden, C., Thompson, E., Hearne, M. \& Wald, D. Shakemap v4 manual: Technical manual, user's guide, and software guide (U S. Geological Survey, 2020).

38. Ceferino, L., Kiremidjian, A. \& Deierlein, G. Regional multiseverity casualty estimation due to building damage following a Mw 8.8 Earthquake Scenario in Lima, Peru. https://doi.org/10.1193/080617EQS154M (2018).

39. Wald, D., Quitoriano, V., Heaton, T. H. \& Kanamori, H. Relationships between peak ground acceleration, peak ground velocity, and modified Mercalli intensity in California. Earthquake Spectra 15, 557-564 (1999).

40. Grunthal, G. \& European Seismological Commission. Working Group "Macroseismic Scales". European Macroseismic Scale 1998 : EMS-98 (European Seismological Commission, Subcommission on Engineering Seismology, Working Group Macroseismic scales, 1998).

41. Kuyuk, H. S. \& Allen, R. M. Optimal seismic network density for earthquake early warning: a case study from California. Seismol. Res. Lett. 84, 946-954 (2013).

42. Yoon, K. P. \& Hwang, C.-L. Multiple Attribute Decision Making: An Introduction (Sage Publications, 1995).

43. Edwards, W. \& Newman, J. R. Multiattribute Evaluation (Cambridge University Press, 1986).

44. Ismail-Zadeh, A., Matenco, L., Radulian, M., Cloetingh, S. \& Panza, G. Geodynamics and intermediate-depth seismicity in Vrancea (the southeastern Carpathians): current state-of-the art, https://doi.org/10.1016/ j.tecto.2012.01.016 (2012).

45. Sokolov, V. Y., Wenzel, F. \& Mohindra, R. Probabilistic seismic hazard assessment for Romania and sensitivity analysis: a case of joint consideration of intermediate-depth (Vrancea) and shallow (crustal) seismicity. Soil Dyn. Earthquake Eng. https://doi.org/10.1016/ j.soildyn.2008.04.004 (2009).

46. Ionescu, C. et al. An early warning system for deep Vrancea (Romania) earthquakes. In Earthquake Early Warning Systems, (eds Gasparini, P., Manfredi, G. \& Zschau, J.) 343-349 (Springer, 2007).

47. Valentini, A., Visini, F. \& Pace, B. Integrating faults and past earthquakes into a probabilistic seismic hazard model for peninsular Italy. Nat. Hazards Earth Syst. Sci. 17, 2017-2039 (2017).

48. Zuccolo, E., Cremen, G. \& Galasso, C. Comparing the performance of regional earthquake early warning algorithms in Europe. Front. Earth Sci. 9, 686272 (2021).

49. Cremen, G., Zuccolo, E. \& Galasso, C. Accuracy and uncertainty analysis of selected methodological approaches to earthquake early warning in Europe. Seismol. Res. Lett. 92, 2321-2332 (2021).

50. Klafft, M. \& Meissen, U. Assessing the economic value of early warning systems. In Proceedings of the 8th International Conference on Information Systems for Crisis Response and Management (Lisbon, 2011).

51. Allen, R. M. Probabilistic warning times for earthquake ground shaking in the San Francisco ay Area. Seismol. Res. Lett. 77, 371-376 (2006)

52. Giardini, D., Wössner, J. \& Danciu, L. Mapping Europe's seismic hazard. Transactions 95, 261-268 (2014).

53. Woessner, J. et al. The 2013 European seismic hazard model: key components and results. Bull. Earthquake Eng. 13, 3553-3596 (2015). 
54. de Santis, A., Cianchini, G., Favali, P., Beranzoli, L. \& Boschi, E. The Gutenberg-Richter law and entropy of earthquakes: two case studies in central Italy. Bull. Seismol. Soc. Am. 101, 1386-1395 (2011).

55. Akkar, S., Sandıkkaya, M. A. \& Bommer, J. J. Empirical ground-motion models for point- and extended-source crustal earthquake scenarios in Europe and the Middle East. Bull. Earthquake Eng. 12, 359-387 (2014).

56. Thompson, E. M. \& Worden, C. B. Estimating rupture distances without a ruptureestimating rupture distances without a rupture. Bull. Seismol. Soc. Am. 108, 371-379 (2018)

57. Wald, D. J. \& Allen, T. I. Topographic slope as a proxy for seismic site conditions and amplification https://doi.org/10.1785/0120060267 (2007).

58. Lomax, A., Vireux, J., Volant, P. \& Berge-Thierry, C. Probabilistic earthquake location in 3D and layered models. In Advances in Seismic Event Location (Springer, Dordrecht, 2000).

59. Podvin, P. \& Lecomte, I. Finite difference computation of traveltimes in very contrasted velocity models: a massively parallel approach and its associated tools. Geophys. J. Int. 105, 271-284 (1991).

60. Wagner, M., Husen, S., Lomax, A., Kissling, E. \& Giardini, D. High-precision earthquake locations in switzerland using regional secondary arrivals in a 3-D velocity model. Geophys. J. Int. 193, 1589-1607 (2013).

61. Laske, G., Masters, G., Ma, Z. \& Pasyanos, M. Update on CRUST1.0-a 1-degree global model of Earth's crust. Geophy. Res. Abstr. 15, 2658 (2013).

62. Allen, R. M. et al. Real-time earthquake detection and hazard assessment by ElarmS across California. Geophys. Res. Lett. 36 https://doi.org/10.1029/ 2008GL036766 (2009).

63. Satriano, C. et al. PRESTo, the earthquake early warning system for Southern Italy: concepts, capabilities and future perspectives. Soil Dyn. Earthquake Eng. 31, 137-153 (2011).

64. Cua, G., Fischer, M., Heaton, T. \& Wiemer, S. Real-time performance of the virtual seismologist earthquake early warning algorithm in Southern California. Seismol. Res. Lett. 80, 740-747 (2009).

65. Trugman, D. T., Page, M. T., Minson, S. E. \& Cochran, E. S. Peak ground displacement saturates exactly when expected: Implications for earthquake early warning. J. Geophys. Res. Solid Earth 124, 4642-4653 (2019).

66. Allen, R. M. The elarms earthquake early warning methodology and application across california. In Earthquake Early Warning Systems, (eds Gasparini, P., Manfredi, G. \& Zschau, J.) 21-43 (Springer, 2007).

67. Behr, Y. et al. Anatomy of an earthquake early warning (EEW) alert: predicting time delays for an end-to-end EEW system. Seismol. Res. Lett. 86, 830-840 (2015).

68. Zuccolo, E. et al. Earthquake early warning scenarios at critical facilities in the Eastern Caribbean. Bull. of Earthquake Eng. 14, 2579-2605 (2016).

69. Masi, A., Chiauzzi, L., Nicodemo, G. \& Manfredi, V. Correlations between macroseismic intensity estimations and ground motion measures of seismic events. Bull. Earthquake Eng. 18, 1899-1932 (2020).

70. Rose, A. N., McKee, J. J., Urban, M. L. \& Bright, E. A. LandScan 2018 (2019).

71. Iervolino, I. Performance-based earthquake early warning. Soil Dyn. Earthquake Eng. 31, 209-222 (2011).

72. Goltz, J. D. Introducing Earthquake Early Warning in California-A Summary of Social Science and Public Policy Issues. Tech. Rep. (Governor's Office of Emergency Services, Pasadena, California, 2002).
73. Iervolino, I., Galasso, C. \& Manfredi, G. Information-dependent lead-time maps for earthquake early warning in the Campania region. In 14th World Conference on Earthquake Engineering (Beijing, 2007).

\section{Acknowledgements}

We thank Dr. Alireza Azarbakht and Dr. John Douglas (University of Strathclyde, UK) for helpful feedback on parts of this study. All authors are supported by the European Union's Horizon 2020 research and innovation programme under grant agreement No. 821046, project TURNkey (Towards more Earthquake-resilient Urban Societies through a Multi-sensor-based Information System enabling Earthquake Forecasting, Early Warning and Rapid Response actions; https://earthquake-turnkey.eu/).

\section{Author contributions}

G.C. and C.G. conceived and designed the research. G.C. drafted the written content of the manuscript, which all authors reviewed. G.C. performed the calculations. G.C. and C.G. developed the figures. E.Z. provided EEW and seismic hazard expertise.

\section{Competing interests}

The authors declare no competing interests.

\section{Additional information}

Supplementary information The online version contains supplementary material available at https://doi.org/10.1038/s41467-021-27807-2.

Correspondence and requests for materials should be addressed to Gemma Cremen.

Peer review information Nature Communication thanks Richard Allen, Yannik Behr, David Wald and the anonymous reviewer(s) for their contribution to the peer review of this work. Peer reviewer reports are available.

Reprints and permission information is available at http://www.nature.com/reprints

Publisher's note Springer Nature remains neutral with regard to jurisdictional claims in published maps and institutional affiliations.

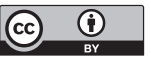

Open Access This article is licensed under a Creative Commons Attribution 4.0 International License, which permits use, sharing, adaptation, distribution and reproduction in any medium or format, as long as you give appropriate credit to the original author(s) and the source, provide a link to the Creative Commons license, and indicate if changes were made. The images or other third party material in this article are included in the article's Creative Commons license, unless indicated otherwise in a credit line to the material. If material is not included in the article's Creative Commons license and your intended use is not permitted by statutory regulation or exceeds the permitted use, you will need to obtain permission directly from the copyright holder. To view a copy of this license, visit http://creativecommons.org/licenses/by/4.0/.

(C) The Author(s) 2022 